\title{
Translatome Profiling of Plum Pox Virus-Infected Leaves in European Plum Reveals Temporal and Spatial Coordination of Defense Responses in Phloem Tissues
}

\author{
Tamara D. Collum, ${ }^{1}$ Andrew L. Stone,${ }^{2}$ Diana J. Sherman, ${ }^{2}$ Elizabeth E. Rogers, ${ }^{2}$ Christopher Dardick, ${ }^{3}$ \\ and James N. Culver ${ }^{1,4,+}$ \\ ${ }^{1}$ Institute for Bioscience and Biotechnology Research, College Park, MD, U.S.A. \\ ${ }^{2}$ USDA, Agricultural Research Service, Foreign Disease-Weed Science Research Unit, Frederick, MD, U.S.A. \\ ${ }^{3}$ USDA, Agricultural Research Service, Appalachian Fruit Research Station, Kearneysville, WV, U.S.A. \\ ${ }^{4}$ Department of Plant Science and Landscape Architecture, University of Maryland, College Park, MD, U.S.A.
}

Accepted 22 July 2019.

Plum pox virus (PPV) is the causative agent of sharka, a devastating disease of stone fruits including peaches, apricots, and plums. PPV infection levels and associated disease symptoms can vary greatly, depending upon the virus strain, host species, or cultivar as well as developmental age of the infected tissues. For example, peaches often exhibit mild symptoms in leaves and fruit while European plums typically display severe chlorotic rings. Systemic virus spread into all host tissues occurs via the phloem, a process that is poorly understood in perennial plant species that undergo a period of dormancy and must annually renew phloem tissues. Currently, little is known about how phloem tissues respond to virus infection. Here, we used translating ribosome affinity purification followed by RNA sequencing to identify phloem- and nonphloem-specific gene responses to PPV infection during leaf development in European plum (Prunus domestica L.). Results showed that, during secondary leaf morphogenesis (4- and 6-week-old leaves), the phloem had a disproportionate response to PPV infection with two- to sixfold more differentially expressed genes (DEGs) in phloem than nonphloem tissues, despite similar levels of viral transcripts. In contrast, in mature 12-week-old leaves, virus transcript levels dropped significantly in phloem tissues but not in nonphloem tissues. This drop in virus transcripts correlated with an 18-fold drop in phloem-specific DEGs. Furthermore, genes associated with defense responses including

Mention of trade names or commercial products in this publication is solely for the purpose of providing specific information and does not imply recommendation or endorsement by the United States Department of Agriculture (USDA). USDA is an equal opportunity provider and employer.

${ }^{\dagger}$ Corresponding author: J. N. Culver; jculver@umd.edu

Funding: USDA National Institute of Food and Agriculture PlantAssociated Microbes and Plant-Microbe Interactions Program grant number 2015-67013-23004, National Science Foundation Division of Integrative Organismal Systems grant number ISO-1644713 and USDA ARS appropriated project 8044-22000-044-00D.

*The $e$-Xtra logo stands for "electronic extra" and indicates that three supplementary figures and three supplementary tables are published online.

The author(s) declare no conflict of interest.

This article is in the public domain and not copyrightable. It may be freely reprinted with customary crediting of the source. The American Phytopathological Society, 2020.
RNA silencing were spatially coordinated in response to PPV accumulation and were specifically induced in phloem tissues at 4 to 6 weeks. Combined, these findings highlight the temporal and spatial dynamics of leaf tissue responses to virus infection and reveal the importance of phloem responses within a perennial host.

Keywords: defense signaling pathways, plant gene expression, plant response to pathogens, virus-plant interactions

In perennial hosts such as European plum (Prunus domestica L.) the onset of bud break and leaf development at the beginning of each growing season provides a new set of tissues for the spread and replication of infecting viruses. It is the biological impact of the virus on this newly developing tissue that often underlies the seasonal disease response (Culver and Padmanabhan 2007; Pallas and García 2011). This impact is likely to be highly dynamic, with temporal and tissue specificity for both virus-induced responses and corresponding host counter responses. Unfortunately, little information on the dynamics of these host responses currently exists, particularly for specific tissues, cell types, and developmental stages. This lack of information is especially acute in perennial hosts where chronic infections can persist for years. Understanding the dynamics of virus infection on host processes will be an important step toward developing better strategies to monitor and mitigate virus-induced diseases.

Plum pox virus (PPV) is one of the most economically important pathogens of stone fruits and can lead to reduced fruit quality, premature fruit drop, and a shortened lifespan (Cambra et al. 2006; García et al. 2014; Németh 1994). PPV belongs to the Potyvirus genus in the family Potyviridae. PPV moves long distances through the phloem vasculature. Phloem transport is a key step in the establishment of systemic disease, but how this process occurs at the molecular level is not well-understood. Initial infection by the virus occurs in epidermal cells during aphid probing or the virus can also be acquired through grafting to infected rootstocks (García et al. 2014; Gildow et al. 2004; Hadidi et al. 2011; Moreno et al. 2009; Powell et al. 1995; Revers and García 2015). To reach the phloem companion cells, the virus must first cross several cell borders moving cell-tocell through plasmodesmata (Ganusova and Burch-Smith 2019; Hipper et al. 2013; Revers and García 2015). Companion cells are connected to neighboring sieve elements by specialized 
branched plasmodesmata known as pore-plasmodesma units (van Bel and Kempers 1997). Once the virus has entered the sieve elements, it travels from source to sink tissues along with the flow of photosynthates (Cronin et al. 1995).

Viral movement across cell borders and into phloem tissues requires specific interactions between virus and host components, however, these interactions are not well-characterized (Folimonova and Tilsner 2018; Hipper et al. 2013). Viral proteins required for PPV long-distance movement through phloem tissues include $\mathrm{VPg}, 6 \mathrm{~K} 2$, and coat protein (CP) (Revers and García 2015). Less understood are the host proteins and pathways involved in PPV phloem loading and long-distance movement. Host factors that assist the long-distance movement of potyviruses have yet to be identified. In contrast, host factors that restrict the long-distance movement of PPV have been described. The best characterized are the RTM genes, of which RTM1 and RTM2 have been shown to be expressed in phloem tissues (Chisholm et al. 2000, 2001; Whitham et al. 2000). As a first step to identify additional host genes and pathways that may impact PPV long-distance movement, we sought to identify changes to host gene expression specifically in phloem tissues during leaf development, using next generation RNA sequencing (RNA-seq).

A few studies have used high-throughput RNA-seq technologies to characterize host responses to PPV in Prunus species. The transcriptomes of GF305 peach leaves were analyzed after PPV infection and symptom development, and 222 differentially expressed genes (DEGs) were identified in symptomatic leaves (Rubio et al. 2015b). In plum, a variety named 'Jojo' that displays a hypersensitive response to PPV was analyzed using RNA-seq, and 3,020 DEGs were identified in response to PPV infection (Rodamilans et al. 2014). In apricot, RNA-seq has been used to identify DEGs in susceptible and resistant cultivars after PPV infection (Rubio et al. 2015a; Zuriaga et al. 2018). In two independent studies, susceptible apricot cultivars were found to have more DEGs after PPV infection than resistant cultivars (Rubio et al. 2015a; Zuriaga et al. 2018). While these studies have given deeper insight into the changes that occur during PPV infection in Prunus spp. and demonstrate the power of RNA-seq to answer questions about PPV and Prunus biology, they did not address temporal and spatial impacts of a PPV infection, particularly for the phloem.

Tissue-specific sequencing of phloem-associated mRNAs has lagged, in part due to the technical difficulty of phloem sampling. It can be challenging to physically separate phloem from surrounding tissues. Common techniques such as phloem bleeding can disrupt the pressurized companion cell-sieve element system and can lead to the introduction of components from neighboring cells into the phloem stream (Dinant and Kehr 2013; Turgeon and Wolf 2009). In this study, a newer approach called translating ribosome affinity purification (TRAP) combined with RNA-seq was used to isolate and characterize phloem-associated mRNAs (Reynoso et al. 2015). TRAP is based on the expression of an epitope-tagged ribosomal protein (RPL18) that enables the immunopurification of assembled ribosomes. The immunopurified mRNAs bound to ribosomes are collectively referred to as the translatome. Here, a modified TRAP approach was used to specifically express the tagged RPL18 in phloem cells, using two phloem tissuespecific promoters (pSUC2 and pSULTR2;2). pSUC2 drives expression predominately in companion cells, whereas pSULTR2;2 expresses in both companion cells and bundle sheath cells (Collum and Culver 2017; Collum et al. 2019; Mustroph et al. 2009). By comparing the results from plant lines expressing RPL18 under control of pSUC2 or pSULTR2;2 to those from lines expressing RPL18 driven by near-constitutive cauliflower mosaic virus (CaMV) p35S promoter, phloem- and nonphloemspecific DEGs can be discriminated from each other. This method was previously used to identify phloem-associated mRNAs during leaf development in healthy European plums (Collum et al. 2019).

The objective of this study was to identify tissue-specific responses to PPV in developing leaves of European plum. Leaf samples were taken at 2, 4, 6, and 12 weeks post-cold induced dormancy. These developmental stages primarily cover secondary morphogenesis, during which leaf expansion and tissue differentiation occur through leaf maturation (Bar and Ori 2014). Results indicated that phloem is highly responsive to PPV infection at the 4- and 6-week developmental timepoints compared with nonphloem leaf tissues. However, at 12 weeks, phloem responses were significantly reduced in comparison with the nonphloem. These findings correlate with the level of translating viral RNAs present at each sampling time, indicating that virus activity and host responses dynamically shift within the phloem depending on the developmental status of the leaf. To our knowledge, this is the first report to examine PPVinduced changes at the tissue-specific level. The spatiotemporal dynamics of virus infection levels and host gene responses within developing leaves are discussed.

\section{RESULTS}

\section{Isolation of mRNAs associated with translating ribosomes from PPV-infected leaves.}

To identify specific tissue-associated mRNAs that are altered during PPV infection, we utilized previously generated transgenic European plum (Prunus domestica L.) lines that express a tagged ribosomal protein RPL18 from either two phloem-specific promoters, pSUC2 or pSULTR2;2, or the more ubiquitously expressed CaMV 35S promoter (Collum et al. 2019). European plum trees were infected with PPV strain Penn7, by aphid transmission, in a BSL3 greenhouse. PPV-infected trees were confirmed using quantitative reverse transcription-PCR (qRT-PCR) with primers specific for the PPV CP (Schneider et al. 2004).

To confirm that HF-RPL18 transgene expression was not altered during virus infection, leaf tissue was collected from infected and uninfected trees and total RNA was isolated for qRT-PCR. Consistent with previous results, HF-RPL18 expression was greater in $\mathrm{p} 35 \mathrm{~S}$ lines as compared with pSULTR2;2 and pSUC2 lines (Collum et al. 2019). We also found no significant differences in the expression of the three HF-RPL18 constructs between infected and uninfected samples (Supplementary Fig. S1). In addition, FLAG-tagged polysomemRNA complexes were purified, and RNA quantity and quality were determined. Results from these studies found no significant difference in the amount or quality of mRNAs recovered from infected or uninfected leaf samples (Supplementary Fig. S2). Together these results indicate that HFRPL18-expressing European plums can be used to capture translating mRNAs during PPV infection.

\section{Phloem-associated translatome analysis.}

After European plum trees were infected with PPV, a cold induced dormancy treatment of 60 days was used to mimic the period of winter dormancy. Phloem tissues are renewed annually after dormancy in newly developing leaves and viruses spread through the phloem to this new growth. To determine the impact this process has on host phloem gene expression, we isolated translating mRNAs from European plum leaves at 2, 4, 6, and 12 weeks post-cold induced dormancy (Fig. 1A). Leaf tissue was collected over two consecutive dormancy and vegetative growth cycles for a total of 100 samples. For the pSUC2 
and $\mathrm{p} 35 \mathrm{~S}$ trees, samples were taken from three healthy and three PPV-infected trees; for pSULTR2;2 trees, samples were taken from two healthy and two PPV-positive trees. Each sample generated 32 to 105 million 150-bp paired-end reads (Supplementary Table S1). Reads were mapped using the CLC Genomics Workbench with the related peach (Prunus persica) genome as a reference (Verde et al. 2017).

After filtering and trimming raw reads, 33 to $84 \%$ of reads from each sample mapped to the reference peach genome, with a median mapping percent of $78 \%$. Mapping percentages in this range are typical for Prunus RNA-seq experiments, especially when mapping to a reference genome from a closely related species (Collum et al. 2019; Rubio et al. 2015a and b). Unmapped reads may also represent novel splice junctions or unannotated transcripts. Principal component analysis (PCA) showed that the six samples with the lowest mapping percentages (33 to $60 \%$ ) still clustered with the other 94 samples by leaf age and tissue type. Thus, despite the low mapping percentages, we chose to include these samples in subsequent analyses. In addition, PCA showed that all samples clustered by age with a separation on principal component 1 of $16.8 \%$ and by promoter with a separation on principal component 2 of $12.4 \%$ (Supplementary Fig. S3).

To identify phloem-associated genes, pair-wise comparisons between uninfected pSUC2 or pSULTR2;2 samples and uninfected p35S samples were performed. Differential gene expression analysis was done using the CLC Genomics Workbench RNA-seq tool, using a threshold of fold change greater than 2 and false discovery rate (FDR) $P$ value less than 0.05 . A total of 2,350 genes were identified as phloem-enriched for at least one timepoint. When compared with published healthy European plum translatome results, we found 1,204 of 2,350
(51\%) phloem-enriched genes identified in this study were previously reported (Supplementary Table S2) (Collum et al. 2019).

\section{PPV viral RNAs associated with ribosomes.}

Viral translating RNAs were quantified over the course of leaf development by mapping filtered sequencing reads to the PPV Penn7 genome (GenBank accession EF640935) (Schneider et al. 2011). Mapped PPV reads were normalized for differences in sequencing depth between samples by dividing by the total reads generated per sample. In phloem samples (pSUC2 and pSULTR2;2), we found that PPV RNAs associated with ribosomes peaked in leaves at 4 to 6 weeks post-cold induced dormancy and then dropped by 12 weeks post-cold induced dormancy (Fig. 1B). In contrast, in control p35S samples, ribosome associated PPV RNAs remained high and at similar levels in leaves at 4 through 12 weeks post-cold induced dormancy (Fig. 1B). We also observed typical PPV disease symptoms including chlorotic ring patterns and blotches on some leaves starting at 6 weeks post-cold induced dormancy (Fig. 1C).

\section{Host responses in European plum leaves infected with PPV.}

To identify DEGs during PPV infection, we used the CLC Genomics RNA-seq tool to do pair-wise comparisons of PPVinfected and noninfected samples for each promoter at each timepoint, using a threshold of absolute value fold change greater than 2 and FDR $P$ value less than 0.05 . The total number of DEGs identified increased as the leaves aged, from 261 DEGs at 2 weeks to 1,094 DEGs at 4 weeks to 2,220 DEGs at 6 weeks and then leveled out at 2,112 genes at 12 weeks
A 2 weeks

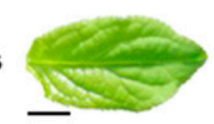

4 weeks
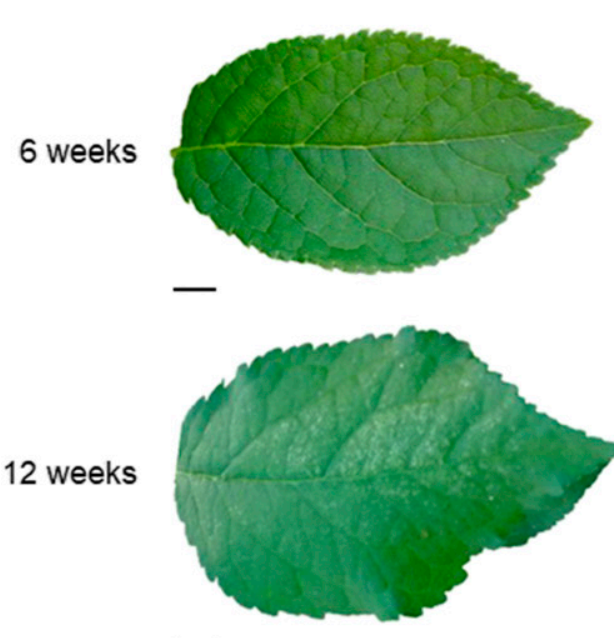

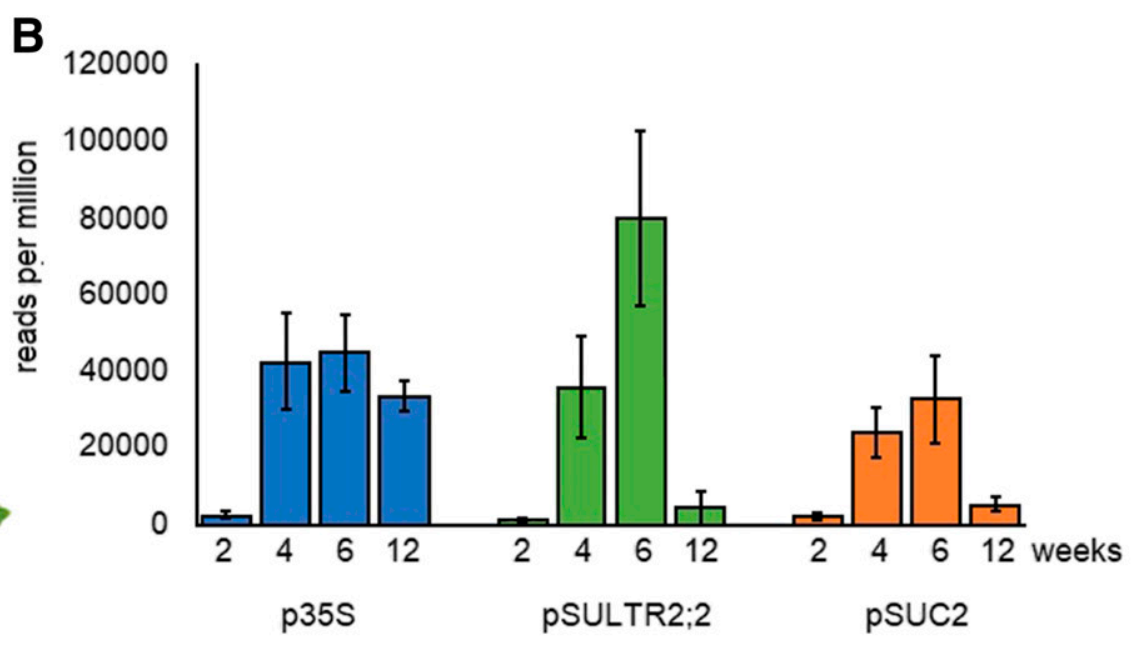

C
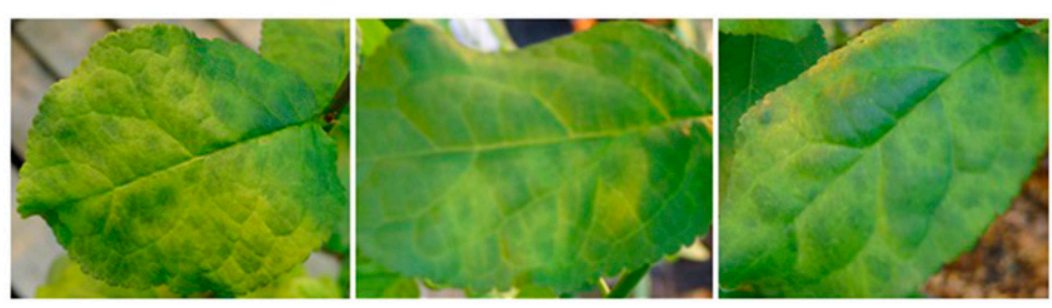

Fig. 1. Plum pox virus (PPV) accumulation in European plum (Prunus domestica L.) leaves. A, Representative photographs of leaves collected at 2, 4, 6, and 12 weeks post-cold induced dormancy. Scale bars represent $1 \mathrm{~cm}$. B, Quantification of PPV RNAs associated with ribosomes isolated at 2, 4, 6, and 12 weeks post-cold induced dormancy. PPV reads per million total reads for each sample are shown. Bars represent the mean \pm standard error. C, PPV disease symptoms in leaves at 6 weeks post-cold induced dormancy. 
(Supplementary Table S3). For each timepoint, we further categorized genes into phloem associated, nonphloem associated, and whole leaf. Phloem associated includes genes altered in one or both of the two phloem (pSUC2 and pSULTR2;2) translatomes, while nonphloem associated includes genes altered only in the p35S translatomes. The whole-leaf category contains genes altered in at least one of the phloem translatomes and the p35S translatome. At 2 weeks post-cold induced dormancy, an equal number of DEGs were identified in phloem and nonphloem tissues (Fig. 2A). At 4 and 6 weeks post-cold induced dormancy six- and twofold more DEGs were identified in phloem tissue than nonphloem tissues, respectively (Fig. 2A). At these timepoints, translating viral RNAs were at similarly high levels in phloem and nonphloem tissues (Fig. 1B). Conversely, at 12 weeks post-cold induced dormancy, nonphloem-associated DEGs were 31-fold greater than phloem-identified DEGs (Fig. 2A). At the 12-week timepoint, translating viral RNAs remained high in nonphloem tissues but were greatly reduced in phloem tissues (Fig. 1B). Together, this suggests the number of host DEGs positively correlates with the accumulation of ribosome-associated PPV RNAs. Furthermore, the phloem is disproportionately responsive to PPV infection at 4 and 6 weeks post-cold induced dormancy, when translating PPV levels are high in phloem and nonphloem tissues.

DEGs were further grouped into up- and downregulated gene sets. Interestingly, we observed different patterns of regulation between phloem and nonphloem tissues. At 2 weeks post-cold induced dormancy, in both phloem and nonphloem tissues, most DEGs were down-regulated (75 and $76 \%$ of genes, respectively) (Fig. 2B). Conversely, at 4 weeks post-cold induced dormancy, $81 \%$ of phloem-associated genes were up-regulated, compared with only $40 \%$ of nonphloem genes (Fig. 2B). By 6 weeks, there was a more equal split, with $50 \%$ of phloem genes and $45 \%$ of nonphloem genes upregulated (Fig. 2B). At 12 weeks, most genes were downregulated, $65 \%$ in phloem tissues and $60 \%$ in nonphloem tissues (Fig. 2B). These results indicate more genes are being up-regulated earlier in phloem tissues than in nonphloem tissues.

\section{Functional analysis of DEGs.}

To identify categories of genes altered during virus infection, we used gene ontology (GO) enrichment analysis from the
Arabidopsis thaliana best BLAST match for each identified DEG. Analysis was done separately for up- and downregulated genes. Among upregulated genes, we found that genes associated with defense responses, response to wounding, and cellsurface receptor signaling pathways were significantly enriched at 4 and 6 weeks in phloem tissues. These same categories were significantly enriched later (at 6 or 12 weeks) in nonphloem tissues (Fig. 3A). Among downregulated genes, defense responses, response to wounding. and cell communicationrelated genes were significantly enriched only in phloem tissues at 2 weeks. In contrast, genes involved in response to auxin and plant-type cell-wall organization or biogenesis were only significantly enriched as downregulated at 12 weeks in nonphloem tissues (Fig. 3B).

Looking closer at genes that fell within the defense responses' GO category, we observed that there were several upregulated genes involved specifically in antiviral defense acting as part of the RNA silencing pathway. During virus infection, viral-derived double-stranded RNAs or structured single-stranded RNAs can be recognized by the host plant and converted to small interfering RNAs (siRNAs) by dicer-like (DCL) proteins. Host RNA-dependent RNA polymerases (RDRs) amplify the production of viral derived siRNAs. siRNAs then associate with argonaute (AGO) proteins and target complementary sequences for silencing (Qi et al. 2009; Zhang et al. 2015). In this study, we found three DCL2 homologs, six RDR1 homologs, RDR6, AGO4, and AGO5 upregulated during PPV infection (Fig. 4).

Additional categories of DEGs involved in defense responses were further analyzed using MapMan (Thimm et al. 2004; Usadel et al. 2005). We found 149 genes altered during PPV infection associated with MapMan BIN 20.1.07 stress.biotic.PRproteins (Fig. 5A). This defense category includes pathogenesisrelated $(P R)$ genes such as $P R I$ as well as predicted resistance $(R)$ genes that contain nucleotide binding sites (NBS) and leucine rich repeats (LRR). We found 125 of 149 (84\%) of these defense genes were up-regulated during at least one timepoint. Among upregulated genes, 34 of $125(27 \%)$ were only altered in phloem tissues while 38 of $125(30 \%)$ were only altered in nonphloem tissues. Interestingly, defense genes specific to phloem tissues were up-regulated only at 4 (11 of 34 genes) and 6 weeks (32 of 34 genes). While upregulation of defense genes specific to nonphloem tissues occurred at 4 ( 7 of 38 genes), 6 (28 of 38), and 12 weeks ( 24 of 38) (Fig. 5A). The remaining 53
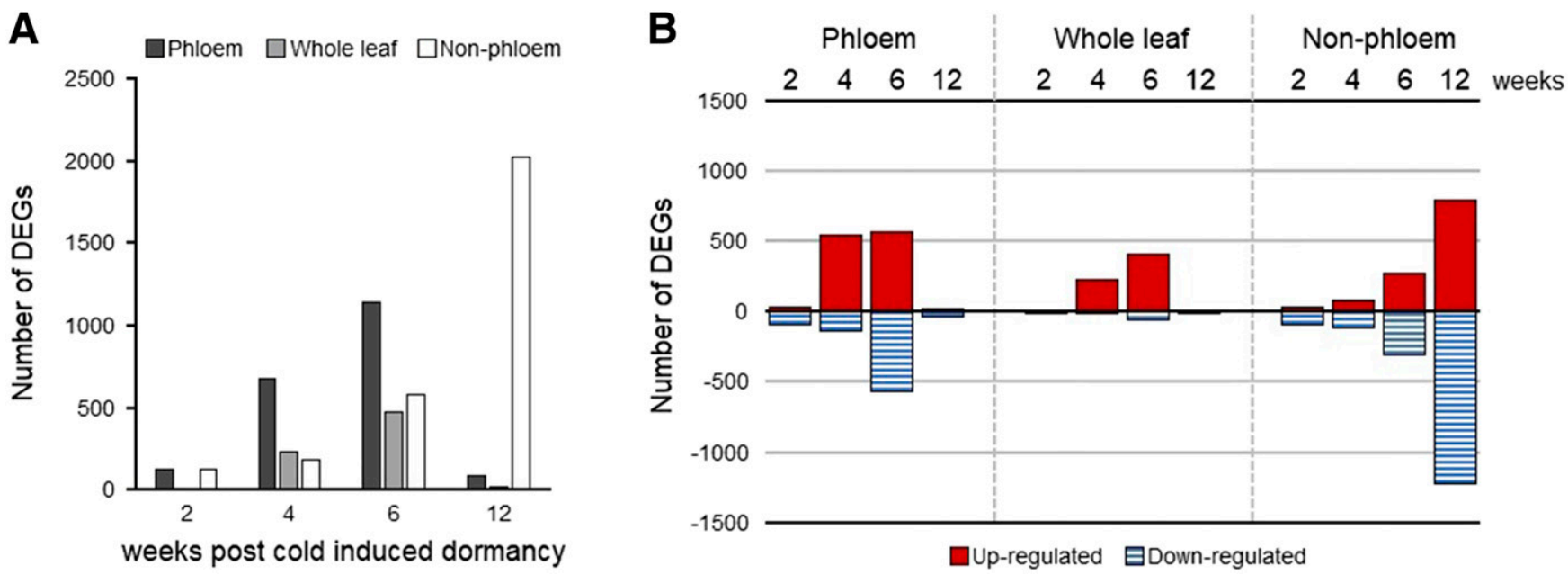

Fig. 2. Host response to plum pox virus (PPV) infection in phloem and nonphloem tissues. A, Number of differentially expressed genes (DEGs) altered in response to PPV in phloem, whole leaf, and nonphloem tissues at four developmental stages. B, Total number of DEGs upregulated or downregulated in response to PPV infection. 
of $125(42 \%)$ genes were up-regulated in both phloem and nonphloem tissues; however, the timing of upregulation was distinctly different. In phloem tissues, we again observed upregulation only at 4 (40 of 53 genes) and 6 weeks (49 of 53). In contrast, in nonphloem tissues, upregulation occurred at 4 (17 of 53 genes), 6 (46 of 53), and 12 weeks (42 of 53). PR genes upregulated during PPV infection included a predicted homolog of PRI (Prupe.8g153800) and three predicted homologs of PR5 (Prupe.7g050700, Prupe.7g050900, Prupe.7g051300). We found $P R I$ and $P R 5$ genes were all up-regulated at 4 weeks in phloem tissues, while they were only up-regulated at 6 or 12 weeks in nonphloem tissues. The earlier activation of $P R$ genes and predicted $R$ genes in phloem tissues suggests defense responses are initiated first in phloem tissues during virus infection.

Another category of genes primarily upregulated during PPV infection were receptor kinases (MapMan BIN 30.2 signaling.receptor kinases) (Fig. 5B). We found a total of 284 receptor kinases altered during PPV infection, with 16 also characterized as $P R$ genes (MapMan BIN 20.1.07 stress.biotic. PR-proteins). Again, we found earlier upregulation in phloem tissues at 4 and 6 weeks post-cold induced dormancy, with 78 and 85 receptor kinase genes, respectively, uniquely upregulated during PPV infection, while, in 12-week-old phloem tissues, there was only one receptor kinase gene that was significantly up-regulated (Fig. 5B). In nonphloem tissues, upregulation of receptor kinases primarily occurred later, at 6 and
12 weeks post-cold induced dormancy, with 64 and 166 receptor kinase genes significantly upregulated, respectively, while, at 4 weeks, only 19 receptor kinase genes were upregulated in nonphloem tissues (Fig. 5B). This finding further indicates that defense signaling is occurring earlier in phloem tissues than in nonphloem tissues.

We also identified families of transcription factors that were altered during PPV infection. Transcription factors belonging to the $W R K Y$ and NAC families were up-regulated in phloem and nonphloem tissues. While transcription factors belonging to the $M Y B$ and $b H L H$ families were were primarily downregulated in nonphloem tissues (Fig. 6). These transcription factor families have all been associated with plant defense responses (Birkenbihl et al. 2017; Dubos et al. 2010; Puranik et al. 2012; Song et al. 2013; Tsuda and Somssich 2015). Again, we observed differences in the temporal regulation of genes within the phloem and nonphloem tissues. NAC and $W R K Y$ genes were found to be significantly upregulated only at 2 and 4 weeks in phloem tissues. In contrast, in nonphloem tissues, $N A C$ and $W R K Y$ genes were primarily up-regulated at 12 weeks (Fig. 6A and B). MYB and $b H L H$ transcription factors were primarily down-regulated at 12 weeks post-cold induced dormancy in nonphloem tissues, while there was no significant regulation of these genes in phloem tissues at the same timepoint (Fig. 6C and D).

Additional categories of genes that were down-regulated included genes involved in cell-wall modifications, $\beta$-1,3-glucanases,
A

\section{Up-regulated genes}

Phloem Non-phloem

24612

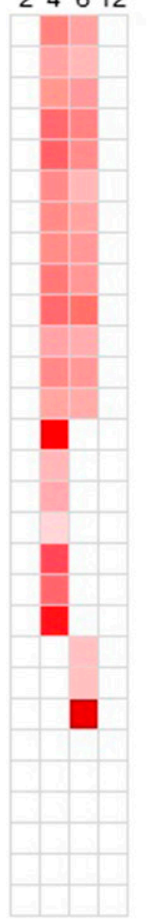

$$
24612 \text { weeks }
$$

respone to fungus

defense response to bacterium regulation of defense response

response to chitin

response to wounding

defense response to other organism

response to bacterium

cell surface receptor signaling pathway

innate immune response

response to salicylic acid

defense response

response to antibiotic

response to drug

systemic aquired resistance

response to oxidative stress

response to cadmium ion

response to abiotic stimulus

response to oomycetes

response to jasmonic acid

flavonoid metabolic process

response to salt stress

protein phosphorylation

recognition of pollen

plant-type hypersensitive response

toxin metabolic process

response to light intensity

response to toxic substance

response to water

regulation of hormone levels
B

\section{Down-regulated genes}

Phloem Non-phloem

$24612 \quad 24612$ weeks

cellular response to stimulus

cell communication

response to external stimulus

defense response

response to wounding

sesquiterpenoid metabolic process

monocarboxylic acid biosynthetic process

fatty acid metabolic process

oxidation-reduction process

lipid biosynthetic process

plant-type cell wall modification

xylan metabolic process

plant-type cell wall organization or biogenesis

phenylpropanoid biosynthetic process

transmembrance receptor kinase signaling pathway

cellular developmental process

response to auxin
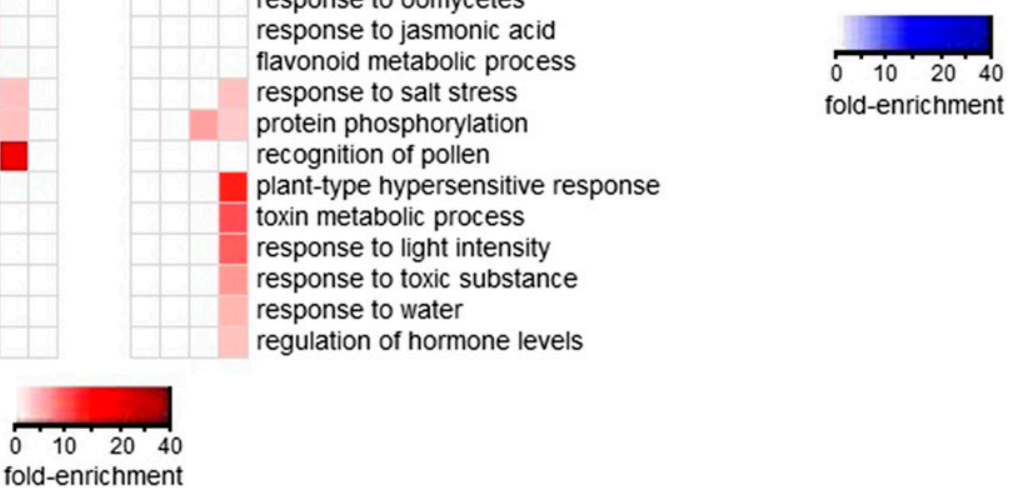

Fig. 3. Gene ontology (GO) enrichment analysis of differentially expressed genes in phloem and nonphloem tissues. A, Heatmap showing significantly enriched (false discovery rate [FDR] $P$ value less than 0.05 ) GO biological processes among upregulated genes in phloem and nonphloem tissues. B, Heatmap showing significantly enriched (FDR $P$ value less than 0.05) GO biological processes among downregulated genes in phloem and nonphloem tissues. The $x$ axis displays weeks post-cold induced dormancy. Darker red or blue shading indicates a greater fold enrichment of GO terms. White indicates there was no significant enrichment. 


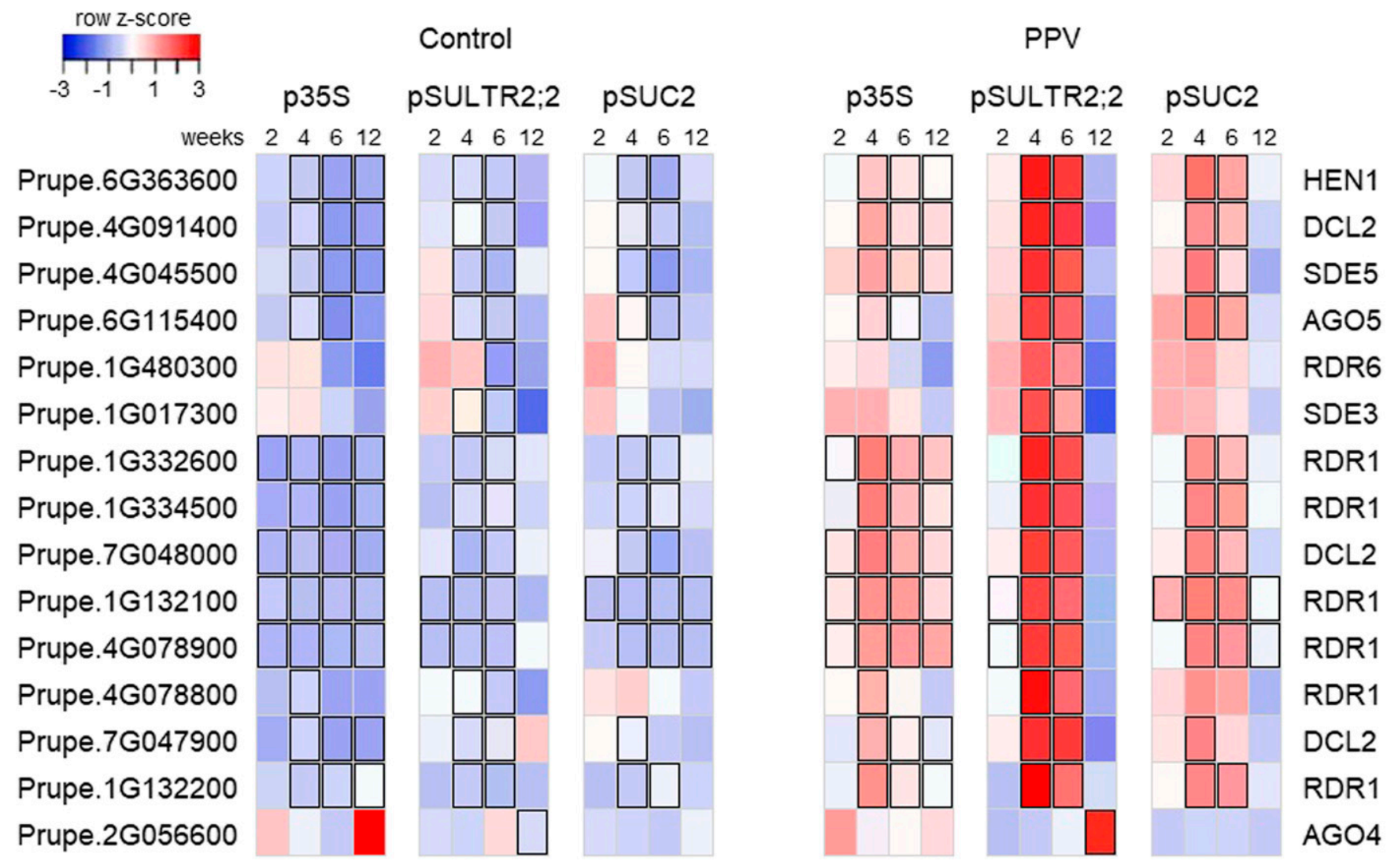

Fig. 4. RNA silencing genes altered during plum pox virus (PPV) infection. Heatmap shows changes to gene expression in Prunus domestica L. leaves at 2, 4, 6, and 12 weeks post-cold induced dormancy with and without PPV infection. Blocks represent the mean fragments per kilobase of transcript per million reads value on a $\log _{2}$ scale with z-scaling by row. Boxed genes are significantly altered (false discovery rate $P$ value $<0.05$ ). Gene names from Arabidopsis thaliana best BLAST matches are shown to the right of the heatmap.

A

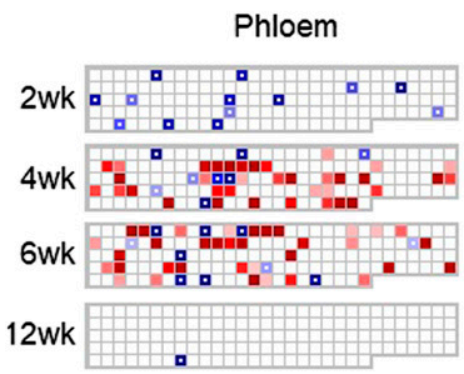

PR genes

Non-phloem

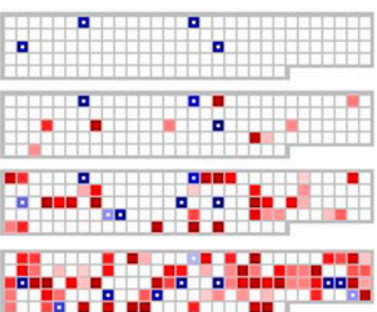

B

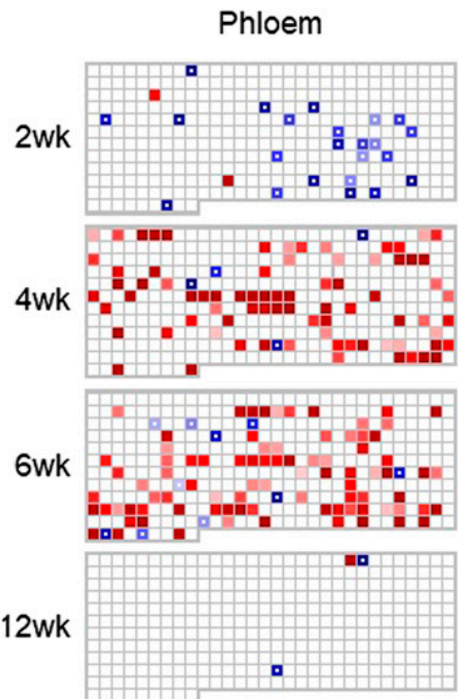

Receptor kinases

\section{Non-phloem}

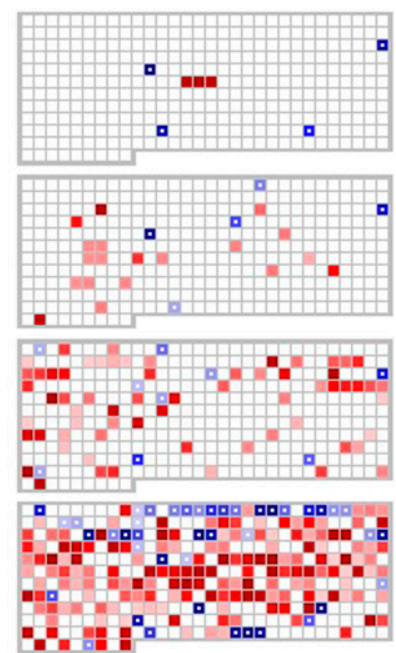

Log2 (fold change)

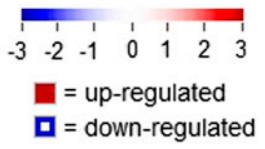

Fig. 5. A, Heatmaps of pathogenesis-related $(P R)$ genes and B, receptor kinase genes significantly altered during plum pox virus (PPV) infection at $2,4,6$, and 12 weeks post-cold induced dormancy. The $\log _{2}$-fold change of PPV samples compared with healthy controls is shown. Each square represents an individual gene. Red-filled squares represent upregulated genes. Blue open squares represent downregulated genes. 
and genes associated with auxin responses. These gene categories were primarily down-regulated in nonphloem tissues at 12 weeks (Fig. 7). For example, 20 genes involved in cell-wall degradation were down-regulated two to 36 -fold in 12 -weekold nonphloem tissues but remained unaltered in infected phloem tissue (Fig. 7A). We also found that $\beta$-1,3-glucanases were down-regulated in nonphloem tissues at 6 and 12 weeks post-cold induced dormancy. In contrast, $\beta$-1,3-glucanases are primarily up-regulated in phloem tissues at 4 weeks, down-regulated at 6 weeks, and not significantly altered at 12 weeks (Fig. 7B). We also observed 25 auxin-responsive genes were down-regulated at 12 weeks in nonphloem tissues while auxin genes were not significantly altered in phloem tissues at 12 weeks (Fig. 7C).

A



C

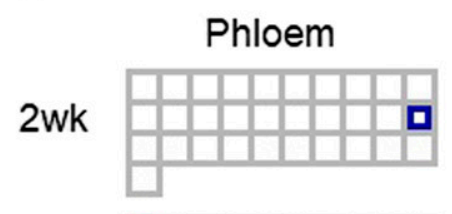

$4 \mathrm{wk}$

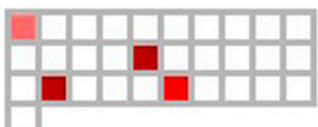

$6 w k$

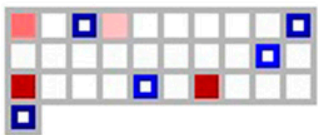

$12 w k$

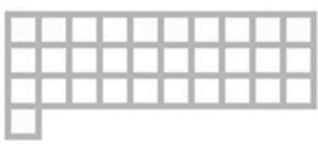

Non-phloem
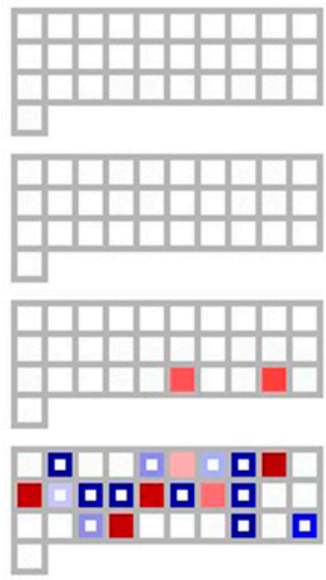

$$
\begin{aligned}
& \text { Log2 (fold change) } \\
& 1 \quad 1 \quad 1 \quad 1 \quad 1 \\
& \begin{array}{lllllll}
-3 & -2 & -1 & 0 & 1 & 2 & 3
\end{array} \\
& \text { = up-regulated } \\
& \mathbf{\square}=\text { down-regulated }
\end{aligned}
$$

B

The long-distant transport of plant viruses through the phloem vasculature is a key step in the establishment of systemic disease. Yet, little is known about how virus infection impacts host gene expression in phloem tissues, especially in perennial fruit trees. This is, in part, due to the technical difficulty of physically separating phloem from surrounding tissues. Here, we demonstrate the use of a molecular TRAPseq approach to isolate phloem-specific RNAs associated with ribosomes during PPV infection in $P$. domestica $\mathrm{L}$. leaves at four developmental leaf stages. Translatome analysis identified 2,350 phloem-associated mRNAs, of which 51\% had been previously identified (Collum et al. 2019). Similar

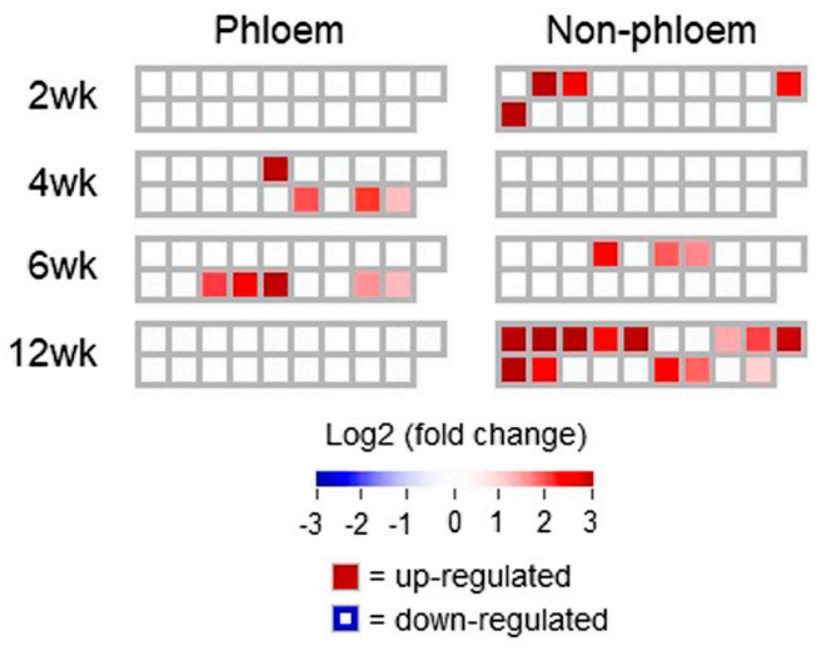

D bHLH

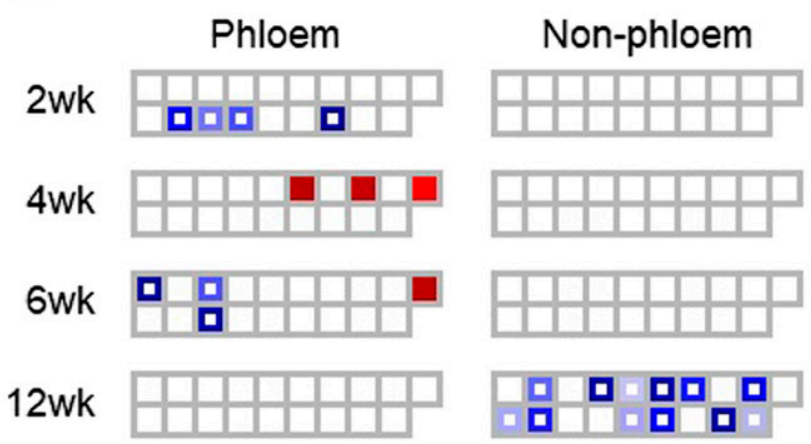

Fig. 6. A, WRKY, B, NAC, C, $M Y B$, and D, $b H L H$ transcription factor family genes altered during plum pox virus (PPV) infection at 2 , 4 , 6 , and 12 weeks post-cold induced dormancy. The $\log _{2}$-fold change of PPV samples compared with healthy controls is shown. Each square represents an individual gene. Red filled squares represent upregulated genes. Blue open squares represent downregulated genes. 
phloem gene comparisons within a single species have identified only an 8 to $22 \%$ overlap (Deeken et al. 2008; Mustroph et al. 2009; Zhao et al. 2005). Thus, we consider this overlap to be significant, especially since these two studies used different aged European plum trees maintained under growth chamber or greenhouse conditions. The 1,204 overlapping phloemassociated genes identified in these studies likely represent the principal $P$. domestica L. phloem mRNAs. GO enrichment analysis of these phloem-associated mRNAs indicates they are significantly enriched for biological processes including response to stress $(17 \%)$, defense responses $(9 \%)$, phosphorylation $(8 \%)$, response to hormones $(8 \%)$, and response to salicylic acid (SA) (2\%). Significantly enriched GO molecular functions included nucleotide binding (12\%), ATP binding

A Cell wall

B

$(10 \%)$, transferase activity (9\%), kinase activity (9\%), and oxidoreductase activity ( $2 \%)$. The identification of phloemassociated prune mRNAs provides a unique resource for assessing tree physiological and environmental responses.

Perennial fruit trees undergo a period of dormancy during the winter, followed by renewed growth in the spring. Viruses that infect these trees spend much of their time in dormant states and, then, must move into the newly emerging tissues through the developing phloem. Information about virus movement and activity in phloem tissues during the breaking of dormancy is scarce. To address this scarcity, PPV-infected European plum trees were subjected to a cold-induced dormancy treatment of 60 days, to mimic the period of winter dormancy, and host and viral translating RNAs were isolated



Fig. 7. Heatmaps of A, cell wall-, B, $\beta$-glucanase-, and $\mathbf{C}$, auxin-associated genes altered during plum pox virus (PPV) infection at $2,4,6$, and 12 weeks post-cold induced dormancy. The $\log _{2}$-fold change of PPV samples compared with healthy controls is shown. Each square represents an individual gene. Redfilled squares represent upregulated genes. Blue open squares represent downregulated genes. 
from leaves collected at 2, 4, 6, and 12 weeks post-cold induced dormancy. We found that, in 2-week-old newly developing leaves, there was an equal number of DEGs in phloem and nonphloem tissues. However, by 4 and 6 weeks post-cold induced dormancy six- and twofold more DEGs were observed in phloem tissues compared with nonphloem tissues. At these developmental stages, translating viral RNAs were also high in both phloem and nonphloem tissues. Similarly, in herbaceous hosts infected with tobacco mosaic virus, the phloem was also disproportionately impacted during viral infection (Collum and Culver 2017). Thus, phloem represents a key responsive tissue during leaf development. Interestingly, in 12-week-old leaves, phloem-associated alterations in response to PPV included only 63 genes, while nonphloemassociated responses encompass 2,024 genes. This dramatic change in older tissue responses correlates with significantly reduced PPV infection levels in the phloem of 12-week-old leaves. The reason for this phloem-specific reduction of PPV in mature leaves is unclear but may be related to the earlier activation of phloem-associated defense genes or the transition of the leaf from photosynthetic sink to source. Combined, this study shows for the first time the spatiotemporal changes that occur during virus infection of a perennial host.

Genes altered in phloem tissues during virus infection could represent host defense responses or virus-induced changes to host pathways that are beneficial for infection. We found that several categories of genes associated with defense responses were primarily up-regulated in both phloem and nonphloem tissues. However, the timing of this upregulation differed, with more defense genes being upregulated earlier, at 4 weeks, in phloem tissues compared with nonphloem tissues. Defenseassociated genes included predicted $R$ genes with NBS-LRR domains, $P R$ genes, and receptor kinases. It was previously reported that LRR-containing genes were up-regulated during PPV infection in plum undergoing a hypersensitive reaction (Rodamilans et al. 2014). However, this is the first study to show phloem-specific upregulation of LRR-containing genes during PPV infection. We identified three toll interleukin 1 receptor-NBS-LRR genes and nine coiled coil-NBS-LRR genes that were only up-regulated in phloem tissues. This phloem subset of predicted $R$ genes implies there are unique defense responses occurring in the phloem during viral infection. Predicted homologs of $P R$ genes $P R 1$ and $P R 5$ were also up-regulated earlier, at 4 weeks, in phloem tissues, compared with 12 weeks in nonphloem tissues. PRl can be induced by a variety of pathogens, including viruses, and has been used as a molecular marker of SA-mediated defense responses (Ryals et al. 1996; Uknes et al. 1992). SA-mediated defense responses have been shown to impact PPV systemic movement. Reduction of SA by expressing the bacterial salicylate hydroxylase $(N a h G)$ in tobacco plants enhanced PPV systemic movement through phloem tissues (Alamillo et al. 2006). SA has also been linked to the regulation of plasmodesmata, which could impact viral movement (Wang et al. 2013). Together, this indicates host defense responses are being activated earlier in phloem tissues than in nonphloem tissues. However, activation of these phloem defense responses is either insufficient in strength or timing and, thus, not able to effectively limit PPV infection and disease.

Additional defense-associated genes also demonstrate unique patterns of expression. These include genes associated with RNA silencing, including DCL endonucleases, RDRs, siRNA methyltransferases (HEN), and AGO proteins (Qi et al. 2009; Zhang et al. 2015). During PPV infection, three predicted homologs of RDR1 and one DCL2 homolog were the first RNA silencing-associated genes to be significantly upregulated, primarily in the nonphloem tissues of 2-week-old leaves. At
4 weeks, an array of silencing-associated genes, including the additional RDR1 and DCL2 homologs AGO5, SDE3/5, and $H E N 1$, are also up-regulated in both phloem and nonphloem tissues. However, the greatest relative levels of silencing activation occurred in phloem tissue derived from the SULTR2;2 promoter, which expresses in companion and bundle sheath cells (Collum and Culver 2017; Collum et al. 2019; Mustroph et al. 2009). This suggests that phloem and its surrounding support cells are highly responsive in the activation of silencing defenses. High expression responses within the vascular bundle could provide a means for the rapid transport of silencing-associated signals, such as siRNAs, both locally into the surrounding leaf tissue as well as systemically through the phloem.

Activation of silencing-associated genes was generally consistent from week 4 through week 6 in both phloem and nonphloem tissues. However, by week 12, we observed a dramatic reduction in the levels of induced-silencing genes within the phloem but not within nonphloem tissues. This reduction corresponds with the specific reduction of PPV infection levels in 12-week-old phloem tissues. The translatome measures ribosome-associated virus genomes that are likely actively contributing to the infection processes. Consistent high levels of ribosome-associated PPV genomes in the nonphloem tissues of 12-week-old leaves appears to maintain the induction of these silencing-associated genes. Combined, these findings indicate that activation of silencing-associated defenses corresponds tightly with active virus infection in a tissue-specific manner.

We found several families of defense-associated transcription factors, including NAC, WRKY, bHLH, and MYB, that were altered during PPV infection (Birkenbihl et al. 2017; Dubos et al. 2010; Puranik et al. 2012; Song et al. 2013; Tsuda and Somssich 2015). Interestingly, all four transcription families displayed some level of upregulation at 4 weeks in phloem tissues. Altered NAC and WRKY genes remained upregulated at week 6 in phloem as well as at week 12 in nonphloem tissues. $W R K Y$ genes upregulated only in phloem tissues at 4 weeks included WRKY6, WRKY18, WRKY33, WRKY40, WRKY50, WRKY51, WRKY53, WRKY65, WRKY70, and WRKY75. All these phloem-altered $W R K Y$ genes have been previously shown to be upregulated in response to SA treatment or bacterial pathogen infection, except for WRKY65 (Dong et al. 2003). WRKY70 has also been shown to be important for SA and jasmonic acid crosstalk (Leon-Reyes et al. 2010; Ren et al. 2008). Additionally, WRKY50 has been shown to activate expression of PRl (Hussain et al. 2018), which we also found was up-regulated at 4 weeks in phloem tissues. $N A C$ genes upregulated in phloem included NAC028, NAC47, NAC85, and NTL9. NTL9 has been shown to be involved in SA synthesis and effector-triggered immunity, and it regulates defense-related genes ICS1, EDS1, PAD4, and PRI (Block et al. 2014; Zheng et al. 2015).

In contrast to the identified $W R K Y$ and $N A C$ altered genes, $b H L H$ genes are primarily down-regulated in week 6 phloem tissues as well as in week 12 nonphloem tissues. bHLH transcription factors have roles in the jasmonic acid signaling pathway, which function antagonistically against SA-mediated pathways (Fonseca et al. 2014; Song et al. 2013; Verma et al. 2016). The general downregulation of $b H L H$ genes and upregulation of $W R K Y$ and NAC genes are thus consistent with SAassociated defense processes being activated in older more developed tissues. MYB factors display a mix of up- and downregulated genes over these same timepoints, which is consistent with their role in regulating diverse stress and developmental responses (Ambawat et al. 2013). Together, the differential regulation of transcription factors in phloem and 
nonphloem tissues supports the spatiotemporal activation of specific SA-associated defense responses during PPV infection.

Additional gene categories that were primarily down-regulated during PPV infection included genes associated with cell-wall modification, $\beta$-1,3-glucanases, and auxin responsive genes. Interestingly, this downregulation occurred primarily in nonphloem tissues and only in 12 -week-old leaves. $\beta$-1,3-glucanases are involved in breaking down callose, whose deposition at plasmodesmata and in phloem sieve tubes can block viral movement (Ganusova and Burch-Smith 2019; Iglesias and Meins 2000; Sjolund 1997). Thus, regulating callose is a potentially important defense response. Interestingly, four $\beta$-1,3-glucanases were up-regulated in 4-week-old phloem tissues. This early upregulation of $\beta$-1,3-glucanases could reduce callose deposition in the phloem plasmodesmata, potentially enhancing viral phloem loading and movement through this tissue. In contrast, eight $\beta-1,3$-glucanases were down-regulated in nonphloem tissues at 12 weeks post-cold induced dormancy. The downregulation of $\beta$-1,3-glucanases could be advantageous for the host and be an attempt to block viral spread. However, the fact that this occurs only late in infection and in nonphloem tissues suggest that these host responses occur too late to prevent viral systemic movement.

We also observed the general downregulation of auxinresponsive genes, primarily in nonphloem tissues at 12 weeks post-cold induced dormancy. Auxin is an important plant hormone involved in many aspects of plant growth and development and also has a role in plant defense responses acting antagonistically to SA (Fu and Wang 2011). Additionally, some viral proteins have been shown to reprogram the auxin signaling pathway, resulting in enhanced viral systemic movement and disease symptoms (Collum et al. 2016; Jin et al. 2016). Auxin-associated proteins were similarly found to be downregulated in Nicotiana benthamiana infected with PPV (Nováková et al. 2018). Together, the downregulation of genes involved in cell-wall modifications, $\beta$-1,3-glucanases, and auxin-responsive genes are consistent with a unique tissuespecific set of host defense responses being activated in mature 12-week-old nonphloem tissues.

In conclusion, the TRAP system has proven to be a useful means to capture tissue-specific mRNAs in a perennial system. Results from this study showed for the first time the dynamic changes that occur in key host tissues during PPV infection over the course of leaf development. It is clear from this study that, in comparison with nonphloem tissues, the phloem is disproportionately responsive to PPV infection upon leaf maturation but that this responsiveness is lost as the leaf ages, resulting in the nonphloem tissues becoming the predominate altered tissue during infection. This finding correlates with tissue-specific PPV infection levels and suggests that the progression of host responses depend upon the presence of active virus infection. How the temporal and tissue-specific expression profiles of these host responses impact PPV infection is yet to be resolved. However, it will be interesting to determine if altering the timing of identified phloem-associated viral defense genes to express prior to peak infection levels can be used to disrupt the normal virus lifecycle and impart new mechanisms of resistance.

\section{MATERIALS AND METHODS}

Plant material, virus inoculations, and growth conditions.

The $P$. domestica L. transgenic plant lines expressing His-FLAG-RPL18 from one of three promoters (pSUC2, pSULTR2;2, or p35S) were described in a previous study (Collum et al. 2019). All virus-infected plant material was maintained in the plant biosafety level 3 containment facility at the United States Department of Agriculture Agriculture Research Service facility at Fort Detrick, Maryland. The PPV-D isolate Penn7 (GenBank accession no. EF640935) used in this study was originally isolated from peach fruit growing on an infected tree in York County, Pennsylvania (Gildow et al. 2004; Schneider et al. 2011). A Myzus persicae aphid colony was maintained inside containment and transmissions were conducted, as previously described (Damsteegt et al. 2007), using symptomatic European plum (P. domestica 'Stanley') leaves as the inoculum source for aphid transmission to transgenic European plum lines. Plants in the quarantine greenhouse were subjected to a cycle of 60 days of cold dormancy $\left(4^{\circ} \mathrm{C}\right)$ followed by 84 to 90 days of growth at normal greenhouse temperatures $\left(27^{\circ} \mathrm{C}\right)$. For each biological replicate, 10 to 15 leaves randomly selected from the canopy were pooled and were immediately frozen in liquid nitrogen and stored at $-80^{\circ} \mathrm{C}$ until RNA isolation. Leaf samples were collected 2, 4, 6, and 12 weeks post cold-induced dormancy during two consecutive vegetative growth cycles.

\section{Isolation of total RNA and qRT-PCR.}

Frozen plant leaves were ground with a mortar and pestle in cold polysome extraction buffer (PEB: $200 \mathrm{mM}$ Tris- $\mathrm{HCl}, \mathrm{pH}$ 9.0, $200 \mathrm{mM} \mathrm{KCl}, 25 \mathrm{mM}$ ethylene glycol tetraacetic acid [EGTA], pH 8.0, $35 \mathrm{mM} \mathrm{MgCl}_{2}, 1 \%$ [vol/vol] octylphenylpolyethylene glycol (Igepal CA-630), 1\% [vol/vol] polyoxyethylene 10 tridecyl ether, $1 \%$ [vol/vol] sodium deoxycholate, $5 \mathrm{mM}$ dithiothereitol [DTT], $1 \mathrm{mM}$ phenylmethylsulfonyl fluoride, $50 \mu \mathrm{g}$ of cycloheximide per milliliter, $50 \mu \mathrm{g}$ of chloramphenicol per milliliter, $0.5 \mathrm{mg}$ of heparin per milliliter). For each sample $100 \mu \mathrm{l}$ of ground plant material was used for total RNA isolation, using the RNeasy plant mini kit (Qiagen, Valencia, CA, U.S.A.), and was combined with $450 \mu$ of RLT lysis buffer plus $\beta$-mercaptoethanol, following the manufacturer's instructions. RNA was eluted in $30 \mu \mathrm{l}$ of nuclease-free water. Total RNA was quantified using a NanoDrop 2000. A total of $300 \mathrm{ng}$ of RNA was pretreated with RQ1 DNase (Promega, Madison, WI, U.S.A.), followed by RT, using the SuperScript III first-strand synthesis system and random hexamer primers (Life Technologies, Carlsbad, CA U.S.A.). qRTPCR was done using the Maxima SYBR green/ROX qPCR master mix (Thermo Fisher Scientific, Cleveland, OH, U.S.A.) on an ABI Prism 7100 (Applied Biosystems, Foster City, CA, U.S.A.), with three technical reps per sample.

Transgene expression was detected using primers $5^{\prime}$-ATT TACAATTACCATGGGACATCAC- $3^{\prime}$ and $5^{\prime}$-CACCACCTCC CTTATCATCATC-3' specific for the His-FLAG-RPL18 transcript. PPV infection was detected using primers $5^{\prime}$-CCAAT

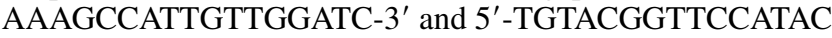
CTTAAGT-3' specific to the PPV CP transcript (Schneider et al. 2004). 18S rRNA, amplified using primers 5'-CGTCCC TGCCCTTTGTACAC-3' and 5'-CGAACACTTCACCGGAT CATT- ${ }^{\prime}$, was used as an internal control for normalization for all samples.

\section{Isolation of translatome RNA.}

Translatome RNA was isolated as previously described (Collum et al. 2019; Reynoso et al. 2015). Briefly, frozen leaf tissue was homogenized in cold PEB, as done for total RNA isolation described above. Samples were centrifuged at $16,000 \times g$ for $15 \mathrm{~min}$ at $4^{\circ} \mathrm{C}$. The supernatant was loaded onto an 8-ml 1.6-M sucrose cushion. The polysome fraction was pelleted by centrifuging the samples at $170,000 \times g$ for $18 \mathrm{~h}$ at $4^{\circ} \mathrm{C}$. The pellet was resuspended in $1 \mathrm{ml}$ of PEB. Anti-FLAG magnetic beads $(50 \mu \mathrm{l})$ (Sigma Chemical Company, St. Louis) were added to the resuspended pellet and were incubated at $4^{\circ} \mathrm{C}$ 
overnight with gentle rocking. The beads were recovered using their magnetic property and were washed four times in wash buffer (200 mM Tris-HCl, pH 9.0, $200 \mathrm{mM} \mathrm{KCl,} 25 \mathrm{mM}$ EGTA, $35 \mathrm{mM} \mathrm{MgCl}$, $5 \mathrm{mM}$ DTT, $50 \mu \mathrm{g}$ of cycloheximide per milliliter, $50 \mu \mathrm{g}$ of chloramphenicol per milliliter). Polysome-RNA complexes were eluted, as previously described (Collum et al. 2019), using $100 \mu \mathrm{l}$ of elution buffer (100 $\mu \mathrm{l}$ of wash buffer, $10 \mu \mathrm{l}$ of of $5 \mathrm{mg} / \mathrm{ml} \mathrm{FLAG}_{3}$ peptide [Sigma Chemical Company], $0.5 \mu \mathrm{l}$ of $2 \mathrm{U}$ of RNAse OUT per milliliter [Thermo Fisher Scientific]), followed by RNA purification using the Qiagen RNeasy kit (Qiagen). Isolated RNA was measured on a NanoDrop 2000 and with the Qubit RNA assay kit (Thermo Fisher Scientific). Quality of the RNA was analyzed using an RNA ScreenTape assay (Agilent Technologies, Palo Alto, CA, U.S.A.).

\section{RNA-seq and analysis.}

cDNA library preparation and paired-end sequencing on the Illumina HiSeq system was done by Genewiz (South Plainfield, NJ, U.S.A.). Reads were trimmed based on quality score and were filtered to remove matches to Illumina adapter sequences. Reads were mapped to the Prunus persica v2.0 genome (International Peach Genome Initiative 2013; Verde et al. 2017) or PPV Penn7 virus genome (GenBank accession EF640935 [Schneider et al. 2011]), using the CLC Genomics Workbench v10.0.1 RNA-seq analysis tool and default parameters (mismatch cost 2 , insertion cost 3 , deletion cost 3 , length fraction 0.8 , similarity fraction 0.8 , max hits for a read 10 (CLC Bio, Aarhus, Denmark). Total reads aligned to genes were used in all subsequent analyses. Differentially expressed genes (DEGs) were identified using the CLC Genomics Workbench differential expression for RNA-seq tool with a cutoff value of greater than twofold and false discover rate (FDR) $P$ value less than 0.05 . The dataset is available under GEO accession number GSE131832.

\section{GO enrichment and heatmap generation.}

GO enrichment analysis of DEGs was performed using the Arabidopsis best BLAST hit and the Panther GO enrichment analysis tool (Thomas et al. 2006). A FDR $P$ value less than 0.05 was used as a cutoff for significant GO enrichment. The analysis was done independently for both up- and downregulated genes. Heatmaps for GO enrichment and the RNA silencing pathway were generated using Heatmapper (Babicki et al. 2016). For the RNA-silencing pathway heatmap (Fig. 4) the $\log _{2}$ (fragments per kilobase of transcript per million reads) value was used with z-scaling by row. MapMan (Thimm et al. 2004; Usadel et al. 2005) was used to display categories of DEGs (Figs. 5, 6, and 7). Colored boxes correspond to the $\log _{2}$ (fold change) values of PPV-infected samples compared with healthy control samples.

\section{ACKNOWLEDGMENTS}

We thank J. Bailey-Serres, University of California Riverside for providing the translatome constructs and $\mathrm{W}$. Schneider for assistance in the initiation of this project.

\section{LITERATURE CITED}

Alamillo, J. M., Saénz, P., and García, J. A. 2006. Salicylic acid-mediated and RNA-silencing defense mechanisms cooperate in the restriction of systemic spread of plum pox virus in tobacco. Plant J. 48:217-227.

Ambawat, S., Sharma, P., Yadav, N. R., and Yadav, R. C. 2013. MYB transcription factor genes as regulators for plant responses: An overview. Physiol. Mol. Biol. Plants 19:307-321.

Babicki, S., Arndt, D., Marcu, A., Liang, Y., Grant, J. R., Maciejewski, A., and Wishart, D. S. 2016. Heatmapper: Web-enabled heat mapping for all. Nucleic Acids Res. 44 (W1):W147-W153.
Bar, M., and Ori, N. 2014. Leaf development and morphogenesis. Development 141:4219-4230.

Birkenbihl, R. P., Liu, S., and Somssich, I. E. 2017. Transcriptional events defining plant immune responses. Curr. Opin. Plant Biol. 38:1-9.

Block, A., Toruño, T. Y., Elowsky, C. G., Zhang, C., Steinbrenner, J., Beynon, J., and Alfano, J. R. 2014. The Pseudomonas syringae type III effector HopD1 suppresses effector-triggered immunity, localizes to the endoplasmic reticulum, and targets the Arabidopsis transcription factor NTL9. New Phytol. 201:1358-1370.

Cambra, M., Capote, N., Myrta, A., and Llácer, G. 2006. Plum pox virus and the estimated costs associated with sharka disease. EPPO Bull. 36: 202-204.

Chisholm, S. T., Mahajan, S. K., Whitham, S. A., Yamamoto, M. L., and Carrington, J. C. 2000. Cloning of the Arabidopsis RTM1 gene, which controls restriction of long-distance movement of tobacco etch virus. Proc. Natl. Acad. Sci. U.S.A. 97:489-494.

Chisholm, S. T., Parra, M. A., Anderberg, R. J., and Carrington, J. C. 2001. Arabidopsis RTM1 and RTM2 genes function in phloem to restrict long-distance movement of tobacco etch virus. Plant Physiol. 127:1667-1675.

Collum, T. D., and Culver, J. N. 2017. Tobacco mosaic virus infection disproportionately impacts phloem associated translatomes in Arabidopsis thaliana and Nicotiana benthamiana. Virology 510:76-89.

Collum, T. D., Lutton, E., Raines, C. D., Dardick, C., and Culver, J. N. 2019. Identification of phloem-associated translatome alterations during leaf development in Prunus domestica L. Hortic. Res. 6:16.

Collum, T. D., Padmanabhan, M. S., Hsieh, Y.-C., and Culver, J. N. 2016. Tobacco mosaic virus-directed reprogramming of auxin/indole acetic acid protein transcriptional responses enhances virus phloem loading. Proc. Natl. Acad. Sci. U.S.A. 113:E2740-E2749.

Cronin, S., Verchot, J., Haldeman-Cahill, R., Schaad, M. C., and Carrington, J. C. 1995. Long-distance movement factor: A transport function of the potyvirus helper component proteinase. Plant Cell 7: 549-559.

Culver, J. N., and Padmanabhan, M. S. 2007. Virus-induced disease: Altering host physiology one interaction at a time. Annu. Rev. Phytopathol. 45:221-243.

Damsteegt, V. D., Scorza, R., Stone, A. L., Schneider, W. L., Webb, K., Demuth, M., and Gildow, F. E. 2007. Prunus host range of plum pox virus (PPV) in the United States by aphid and graft inoculation. Plant Dis. 91:18-23.

Deeken, R., Ache, P., Kajahn, I., Klinkenberg, J., Bringmann, G., and Hedrich, R. 2008. Identification of Arabidopsis thaliana phloem RNAs provides a search criterion for phloem-based transcripts hidden in complex datasets of microarray experiments. Plant J. 55:746-759.

Dinant, S., and Kehr, J. 2013. Sampling and Analysis of Phloem Sap. Pages 185-194 in: Plant Mineral Nutrients: Methods and Protocols. F. J. M. Maathuis, ed. Humana Press, Totowa, NJ.

Dong, J., Chen, C., and Chen, Z. 2003. Expression profiles of the Arabidopsis WRKY gene superfamily during plant defense response. Plant Mol. Biol. 51:21-37.

Dubos, C., Stracke, R., Grotewold, E., Weisshaar, B., Martin, C., and Lepiniec, L. 2010. MYB transcription factors in Arabidopsis. Trends Plant Sci. 15:573-581.

Folimonova, S. Y., and Tilsner, J. 2018. Hitchhikers, highway tolls and roadworks: The interactions of plant viruses with the phloem. Curr. Opin. Plant Biol. 43:82-88.

Fonseca, S., Fernández-Calvo, P., Fernández, G. M., Díez-Díaz, M., Gimenez-Ibanez, S., López-Vidriero, I., Godoy, M., Fernández-Barbero, G., Van Leene, J., De Jaeger, G., Franco-Zorrilla, J. M., and Solano, R. 2014. bHLH003, bHLH013 and bHLH017 are new targets of JAZ repressors negatively regulating JA responses. PLoS One 9:e86182.

Fu, J., and Wang, S. 2011. Insights into auxin signaling in plant-pathogen interactions. Front. Plant Sci. 2:74.

Ganusova, E. E., and Burch-Smith, T. M. 2019. Review: Plant-pathogen interactions through the plasmodesma prism. Plant Sci. 279:70-80.

García, J. A., Glasa, M., Cambra, M., and Candresse, T. 2014. Plum pox virus and sharka: A model potyvirus and a major disease. Mol. Plant Pathol. 15:226-241.

Gildow, F., Damsteegt, V., Stone, A., Schneider, W., Luster, D., and Levy, L. 2004. Plum pox in North America: Identification of aphid vectors and a potential role for fruit in virus spread. Phytopathology 94:868-874.

Hadidi, A., Barba, M., Candresse, T., and Jelkmann, W. 2011. Plum pox virus. Pages 185-197 in: Virus and Virus-Like Diseases of Pome and Stone Fruits. The American Phytopathological Society, St. Paul, MN, U.S.A.

Hipper, C., Brault, V., Ziegler-Graff, V., and Revers, F. 2013. Viral and cellular factors involved in Phloem transport of plant viruses. Front. Plant Sci. 4:154. 
Hussain, R. M. F., Sheikh, A. H., Haider, I., Quareshy, M., and Linthorst, H. J. M. 2018. Arabidopsis WRKY50 and TGA transcription factors synergistically activate expression of PR1. Front. Plant Sci. 9:930.

Iglesias, V. A., and Meins, F., Jr. 2000. Movement of plant viruses is delayed in a $\beta$-1,3-glucanase-deficient mutant showing a reduced plasmodesmatal size exclusion limit and enhanced callose deposition. Plant J. 21:157-166.

The International Peach Genome Initiative. 2013. The high-quality draft genome of peach (Prunus persica) identifies unique patterns of genetic diversity, domestication and genome evolution. Nat. Genet. 45:487-494.

Jin, L., Qin, Q., Wang, Y., Pu, Y., Liu, L., Wen, X., Ji, S., Wu, J., Wei, C., Ding, B., and Li, Y. 2016. Rice dwarf virus p2 protein hijacks auxin signaling by directly targeting the rice OsIAA 10 protein, enhancing viral infection and disease development. PLoS Pathog. 12:e1005847.

Leon-Reyes, A., Du, Y., Koornneef, A., Proietti, S., Körbes, A. P., Memelink, J., Pieterse, C. M. J., and Ritsema, T. 2010. Ethylene signaling renders the jasmonate response of Arabidopsis insensitive to future suppression by salicylic Acid. Mol. Plant-Microbe Interact 23: 187-197.

Moreno, A., Fereres, A., and Cambra, M. 2009. Quantitative estimation of plum pox virus targets acquired and transmitted by a single Myzus persicae. Arch. Virol. 154:1391-1399.

Mustroph, A., Zanetti, M. E., Jang, C. J. H., Holtan, H. E., Repetti, P. P., Galbraith, D. W., Girke, T., and Bailey-Serres, J. 2009. Profiling translatomes of discrete cell populations resolves altered cellular priorities during hypoxia in Arabidopsis. Proc. Natl. Acad. Sci. U.S.A. 106: 18843-18848.

Németh, M. 1994. History and importance of plum pox in stone-fruit production. EPPO Bull. 24:525-536.

Nováková, S., Danchenko, M., Skultety, L., Fialová, I., Lešková, A., Beke, G., Flores-Ramírez, G., and Glasa, M. 2018. Photosynthetic and stress responsive proteins are altered more effectively in Nicotiana benthamiana infected with plum pox virus aggressive PPV-CR versus mild PPV-C cherry-adapted isolates. J. Proteome Res. 17:3114-3127.

Pallas, V., and García, J. A. 2011. How do plant viruses induce disease? Interactions and interference with host components. J. Gen. Virol. 92: 2691-2705.

Powell, G., Pirone, T., and Hardie, J. 1995. Aphid stylet activities during potyvirus acquisition from plants and anin vitro system that correlate with subsequent transmission. Eur. J. Plant Pathol. 101:411-420.

Puranik, S., Sahu, P. P., Srivastava, P. S., and Prasad, M. 2012. NAC proteins: Regulation and role in stress tolerance. Trends Plant Sci. 17: 369-381.

Qi, X., Bao, F. S., and Xie, Z. 2009. Small RNA deep sequencing reveals role for Arabidopsis thaliana RNA-dependent RNA polymerases in viral siRNA biogenesis. PLoS One 4:e4971.

Ren, C.-M., Zhu, Q., Gao, B.-D., Ke, S.-Y., Yu, W.-C., Xie, D.-X., and Peng, W. 2008. Transcription factor WRKY70 displays important but no indispensable roles in jasmonate and salicylic acid signaling. J. Integr. Plant Biol. 50:630-637.

Revers, F., and García, J. A. 2015. Molecular biology of potyviruses. Pages 101-199 in: Advances in Virus Research. Maramorosch, K., and Mettenleiter, T. C., eds. Academic Press, New York.

Reynoso, M. A., Juntawong, P., Lancia, M., Blanco, F. A., Bailey-Serres, J., and Zanetti, M. E. 2015. Translating ribosome affinity purification (TRAP) followed by RNA sequencing technology (TRAP-SEQ) for quantitative assessment of plant translatomes. Pages 185-207 in: Plant Functional Genomics: Methods and Protocols. J. M. Alonso and A. N. Stepanova. Humana Press, New York.

Rodamilans, B., San León, D., Mühlberger, L., Candresse, T., Neumüller, M., Oliveros, J. C., and García, J. A. 2014. Transcriptomic analysis of Prunus domestica undergoing hypersensitive response to plum pox virus infection. PLoS One 9:e100477.

Rubio, M., Ballester, A. R., Olivares, P. M., Castro de Moura, M., Dicenta, F., and Martínez-Gómez, P. 2015a. Gene expression analysis of plum pox virus (sharka) susceptibility/resistance in apricot (Prunus armeniaca L.). PLoS One 10:e0144670.

Rubio, M., Rodríguez-Moreno, L., Ballester, A. R., de Moura, M. C., Bonghi, C., Candresse, T., and Martínez-Gómez, P. 2015b. Analysis of gene expression changes in peach leaves in response to plum pox virus infection using RNA-seq. Mol. Plant Pathol. 16:164-176.
Ryals, J. A., Neuenschwander, U. H., Willits, M. G., Molina, A., Steiner, H. Y., and Hunt, M. D. 1996. Systemic acquired resistance. Plant Cell 8: 1809-1819.

Schneider, W. L., Damsteegt, V. D., Gildow, F. E., Stone, A. L., Sherman, D. J., Levy, L. E., Mavrodieva, V., Richwine, N., Welliver, R., and Luster, D. G. 2011. Molecular, ultrastructural, and biological characterization of Pennsylvania isolates of plum pox virus. Phytopathology 101:627-636.

Schneider, W. L., Sherman, D. J., Stone, A. L., Damsteegt, V. D., and Frederick, R. D. 2004. Specific detection and quantification of plum pox virus by real-time fluorescent reverse transcription-PCR. J. Virol. Methods 120:97-105.

Sjolund, R. D. 1997. The phloem sieve element: A river runs through it Plant Cell 9:1137-1146.

Song, S., Qi, T., Fan, M., Zhang, X., Gao, H., Huang, H., Wu, D., Guo, H., and Xie, D. 2013. The bHLH subgroup IIId factors negatively regulate jasmonate-mediated plant defense and development. PLoS Genet. 9: e1003653.

Thomas, P. D., Kejariwal, A., Guo, N., Mi, H., Campbell, M. J., Muruganujan, A., and Lazareva-Ulitsky, B. 2006. Applications for protein sequencefunction evolution data: mRNA/protein expression analysis and coding SNP scoring tools. Nucleic Acids Res. 34:W645-W650.

Thimm, O., Bläsing, O., Gibon, Y., Nagel, A., Meyer, S., Krüger, P., Selbig, J., Müller, L. A., Rhee, S. Y., and Stitt, M. 2004. MAPMAN: A userdriven tool to display genomics data sets onto diagrams of metabolic pathways and other biological processes. Plant J. 37:914-939.

Tsuda, K., and Somssich, I. E. 2015. Transcriptional networks in plant immunity. New Phytol. 206:932-947.

Turgeon, R., and Wolf, S. 2009. Phloem transport: Cellular pathways and molecular trafficking. Annu. Rev. Plant Biol. 60:207-221.

Uknes, S., Mauch-Mani, B., Moyer, M., Potter, S., Williams, S., Dincher, S., Chandler, D., Slusarenko, A., Ward, E., and Ryals, J. 1992. Acquired resistance in Arabidopsis. Plant Cell 4:645-656.

Usadel, B., Nagel, A., Thimm, O., Redestig, H., Blaesing, O. E., PalaciosRojas, N., Selbig, J., Hannemann, J., Piques, M. C., Steinhauser, D., Scheible, W.-R., Gibon, Y., Morcuende, R., Weicht, D., Meyer, S., and Stitt, M. 2005. Extension of the visualization tool MapMan to allow statistical analysis of arrays, display of corresponding genes, and comparison with known responses. Plant Physiol. 138:1195-1204.

van Bel, A. J. E., and Kempers, R. 1997. The pore/plasmodesm unit; key element in the interplay between sieve element and companion cell. Pages 278-291 in: Progress in Botany. H. D. Behnke, U. Lüttge, K. Esser, J. W. Kadereit, and M. Runge, eds. Springer, Berlin.

Verde, I., Jenkins, J., Dondini, L., Micali, S., Pagliarani, G., Vendramin, E. Paris, R., Aramini, V., Gazza, L., Rossini, L., Bassi, D., Troggio, M., Shu, S., Grimwood, J., Tartarini, S., Dettori, M. T., and Schmutz, J. 2017. The Peach v2.0 release: High-resolution linkage mapping and deep resequencing improve chromosome-scale assembly and contiguity. BMC Genomics 18:225.

Verma, V., Ravindran, P., and Kumar, P. P. 2016. Plant hormone-mediated regulation of stress responses. BMC Plant Biol. 16:86.

Wang, X., Sager, R., Cui, W., Zhang, C., Lu, H., and Lee, J.-Y. 2013. Salicylic acid regulates plasmodesmata closure during innate immune responses in Arabidopsis. Plant Cell 25:2315-2329.

Whitham, S. A., Anderberg, R. J., Chisholm, S. T., and Carrington, J. C. 2000. Arabidopsis $R T M 2$ gene is necessary for specific restriction of tobacco etch virus and encodes an unusual small heat shock-like protein. Plant Cell 12:569-582

Zhang, H., Xia, R., Meyers, B. C., and Walbot, V. 2015. Evolution, functions, and mysteries of plant ARGONAUTE proteins. Curr. Opin. Plant Biol. 27:84-90

Zhao, C., Craig, J. C., Petzold, H. E., Dickerman, A. W., and Beers, E. P. 2005. The xylem and phloem transcriptomes from secondary tissues of the Arabidopsis root-hypocotyl. Plant Physiol. 138:803-818.

Zheng, X. Y., Zhou, M., Yoo, H., Pruneda-Paz, J. L., Spivey, N. W., Kay, S. A., and Dong, X. 2015. Spatial and temporal regulation of biosynthesis of the plant immune signal salicylic acid. Proc. Natl. Acad. Sci. U.S.A. 112:9166-9173.

Zuriaga, E., Romero, C., Blanca, J. M., and Badenes, M. L. 2018 Resistance to plum pox virus (PPV) in apricot (Prunus armeniaca L.) is associated with down-regulation of two MATHd genes. BMC Plant Biol. $18: 25$. 